\title{
O clado Merianthera e as tribos Merianieae e Microliceae (Melastomataceae) na Serra Negra, Minas Gerais ${ }^{1}$
}

The clade Merianthera and the tribes Merianieae and Microlicieae in Serra Negra

Luciana Leitão Justino ${ }^{2,5}$, Fátima Regina Gonçalves Salimena ${ }^{3,5}$, Berenice Chiavegatto ${ }^{4}$ \& Luiz Menini Neto ${ }^{2,3,4}$

\begin{abstract}
Resumo
Apresenta-se um estudo taxonômico do clado Merianthera e das tribos Merianieae e Microlicieae (Melastomataceae) na Serra Negra, localizada no Complexo da Mantiqueira, região sul da Zona da Mata de Minas Gerais, Brasil. O clado Merianthera está representado por Behuria parvifolia, Huberia nettoana e Cambessedesia hilariana, Merianieae está representada apenas por Meriania claussenii, enquanto Microlicieae está representada por Lavoisiera imbricata, Microlicia serpyllifolia, Rhynchanthera dichotoma, Trembleya elegans, Trembleya parviflora e Trembleya phlogiformis. A região vem sofrendo impactos devido à plantação de Pinus e Eucalyptus, especulação imobiliária, visitação desorganizada, coleta ilegal de plantas, bem como o aumento das áreas de pastagem, de modo que várias espécies se encontram sob constante ameaça. Em relação à conservação, deve-se ressaltar as espécies B. parvifolia, H. nettoana e $M$. claussenii, provavelmente ameaçadas de extinção a nível regional ou nacional. No presente artigo são apresentadas chaves de identificação, descrições, ilustrações, informações sobre distribuição geográfica e comentários morfológicos para os táxons desses grupos representados na Serra Negra.
\end{abstract}

Palavras-chave: conservação, flora, Floresta Atlântica, Serra da Mantiqueira, taxonomia.

\begin{abstract}
A taxonomic study of the clade Merianthera and the tribes Merianieae and Microliceae (Melastomataceae) of Serra Negra, located in the southern region of Zona da Mata of Minas Gerais, Brazil, is presented. The clade Merianthera is represented by Behuria parvifolia, Huberia nettoana and Cambessedesia hilariana, Merianieae is represented by Meriania claussenii, while Microlicieae is represented by Lavoisiera imbricata, Microlicia serpyllifolia, Rhynchanthera dichotoma, Trembleya elegans, Trembleya parviflora and Trembleya phlogiformis. The region is suffering environmental impacts due to Pinus and Eucalyptus planting, real-state speculation, disorganized visitation, illegal collection of plants, as well as the use of forest remnants and field areas for grazing. Regarding conservation, it should be highlighted the species B. parvifolia, H. nettoana and M. claussenii, probably threatened with extinction at regional or national levels. Identification keys, descriptions, illustrations, information on the geographical distribution and morphological comments for taxa of these groups in Serra Negra are presented.

Key words: conservation, floristics, Atlantic Forest, Mantiqueira Range, taxonomy.
\end{abstract}

\section{Introdução}

Melastomataceae Juss. reúne cerca de 4.500 espécies, distribuídas em aproximadamente 150 gêneros (Clausing \& Renner 2001), sendo a maioria encontrada nas regiões tropicais e subtropicais do globo (Goldenberg et al. 2012a). No Brasil, ocupa a posição de sexta maior família entre as angiospermas, com 1.372 espécies, amplamente distribuídas pelo país (Goldenberg et al. 2012a; BFG 2015). A família pode ser facilmente reconhecida pelas folhas decussadas, com nervação acródroma, estames geralmente falciformes e

\footnotetext{
${ }^{1}$ Monografia de conclusão de curso da primeira autora.

${ }^{2}$ Universidade Federal de Juiz de Fora, Programa de Pós-graduação em Ecologia, Inst. Ciências Biológicas, R. José Lourenço Kelmer s/n, Martelos, 36036-330, Juiz de Fora, MG, Brasil.

${ }^{3}$ Universidade Federal de Juiz de Fora, Inst. Ciências Biológicas, Depto. Botânica, R. José Lourenço Kelmer s/n, Martelos, 36036-330, Juiz de Fora, MG, Brasil.

${ }^{4}$ Centro de Ensino Superior de Juiz de Fora, R. Luz Interior 345, Estrela Sul, 36030-776, Juiz de Fora, MG, Brasil.

${ }^{5}$ Autora para correspondência: luciana_lj@hotmail.com
} 
anteras poricidas. A grande diversidade de hábitos permite que as Melastomataceae sejam encontradas nas mais diversas formações vegetacionais, com um variável número de espécies (Romero \& Martins 2002). Em Minas Gerais, a família está distribuída em ecossistemas diversos, desde ambientes florestais até cerrados e campos rupestres (Chiavegatto \& Baumgratz 2007; Barberena et al. 2010).

Segundo a classificação proposta por Clausing \& Renner (2001), Melastomataceae está dividida nas subfamílias Melastomatoideae e Kibessioideae, com um total de pelo menos 10 tribos. Dentre os grupos, destacam-se Merianieae Triana e Microlicieae Triana, com aproximadamente 230 e 275-300 espécies respectivamente (Renner 1993; Fritsch et al. 2004), e o clado Merianthera (sensu Goldenberg et al. 2012b) com 63 táxons (Baumgratz 2009b; Rodrigues 2009; BFG 2015). Trabalhos recentes sobre a filogenia da família têm indicado que as tribos propostas não encontram sustentação, como Merianieae e Microlicieae, que sofreram alterações nas análises de Fritsch et al. (2004) e Goldenberg et al. (2012b).

Para Minas Gerais, a maioria dos estudos florísticos tem sido feita em Unidades de Conservação, como no Parque Nacional da Serra do Cipó (Semir et al. 1987), Parque Nacional da Serra da Canastra (Romero \& Martins 2002), Parque Estadual da Serra do Cabral (Candido 2005), Parque Estadual do Caparaó (Faria et al. 2006); Parque Estadual do Ibitipoca (Chiavegatto \& Baumgratz 2007; Barberena et al. 2010), Parque Estadual do Itacolomi (Rolim 2011) e Parque Estadual do Biribiri (Araújo 2013). No entanto, outros estudos importantes de Melastomataceae também reforçam a representatividade do grupo para o território mineiro como um todo (Matsumoto \& Martins 2005; Kinoshita et al. 2007; Silva \& Romero 2008; Rezende et al. 2014; Romero \& Versiane 2014).

Embora os avanços na legislação de Minas Gerais tenham sido consideráveis, o território mineiro sofreu grandes transformações na sua paisagem por ter adotado, no passado, um modelo de desenvolvimento que não priorizou as questões ambientais (Drummond et al. 2005). Dessa forma, levantamentos florísticos em regiões pouco protegidas como a Serra Negra são fundamentais para o conhecimento dos variados grupos botânicos, como vem sendo demonstrado por meio de diversos estudos desenvolvidos por Menini Neto et al. (2009), Abreu et al. (2011), Feliciano \& Salimena (2011), Matozinhos \& Konno (2011), Valente et al. (2011), Blaser et al. (2012), Dutra et al. (2012); Souza et al.
(2012), Mezzonato-Pires et al. (2013), Salimena et al. (2013), Gonzaga et al. (2014) e Oliveira et al. (2014). Esses trabalhos incluem descrições de novas espécies e destacam o alto grau de endemismo, reforçando a importância da Serra Negra para a flora mineira. Dentre as principais famílias botânicas da região, destaca-se Melastomataceae, como a segunda mais representativa, totalizando 56 táxons e 17 gêneros, ficando atrás apenas de Orchidaceae (115 spp.) (Salimena et al. 2013).

No entanto, apesar da grande riqueza de espécies, a região ainda recebe tanto os impactos de uma ampla exploração voltada para o reflorestamento por Pinus e Eucalyptus, quanto para a especulação imobiliária, turismo desordenado, pastagens e coleta ilegal de plantas (Drummond et al. 2005, Gonzaga et al. 2014). Dessa forma, é importante ressaltar a necessidade urgente de estabelecer, por lei, novos limites de fiscalização a fim de contribuir para a conservação da região, onde existem apenas duas Reservas Particulares de Patrimônio Natural (RPPN): São Lourenço do Funil e Serra Negra (Menini Neto et al. 2009; Valente et al. 2011).

Para ampliar o conhecimento da flora da Serra Negra, este trabalho tem como objetivo apresentar o tratamento taxonômico do clado Merianthera e das tribos Merianieae e Microlicieae, de maneira a contribuir para ações que visam à conservação da área em estudo.

\section{Material e Métodos}

A Serra Negra está inserida no Complexo da Mantiqueira, se estendendo pelos municípios de Lima Duarte, Santa Bárbara do Monte Verde, Rio Preto e Olaria entre as coordenadas 21'58'11'S e $43^{\circ} 53^{\prime} 21^{\prime \prime}$. As altitudes variam entre 800 a 1.700 metros com vegetação típica do Domínio Atlântico, representada pelos campos rupestres e remanescentes de Floresta Ombrófila Densa Aluvial, Floresta Ombrófila Densa Montana, Floresta Ombrófila Alto Montana e fragmentos da Floresta Estacional Semidecidual, além de áreas arbustivas e antrópicas (Valente et al. 2011; Salimena et al. 2013). O clima, segundo a classificação de Köppen, é do tipo Cwb com verões úmidos e invernos secos (EMATER 2003).

Uma vez que Melastomataceae possui uma elevada riqueza de espécies, é comum a publicação de trabalhos com o tratamento taxonômico direcionado apenas aos táxons inseridos em tribos ou gêneros específicos, como observado, por exemplo, em Baumgratz et al. (2007), Barberena et al. (2008) e 
Baumgratz \& Souza (2011). Dessa forma, devido à expressividade da família na Serra Negra, o presente estudo limitou-se apenas à taxonomia dos representantes do clado Merianthera (sensu Goldenberg et al. 2012b) e das tribos Merianieae (sensu Goldenberg et al. 2012b) e Microlicieae (sensu Fritsch et al. 2004).

A delimitação dos grupos segue as propostas clássicas de Renner (1993), embora as análises filogenéticas feitas por Fritsch et al. (2004) classifiquem a tribo Microliceae como um grupo monofilético, com a exclusão de cinco gêneros, dentre eles Cambessedesia DC., que passa a fazer parte de uma politomia não resolvida de um grande clado incluindo a maioria das espécies de Melastomataceae. Dessa forma, a fim de incluir o tratamento taxonômico de Cambessedesia hilariana (Kunth.) DC. no presente estudo, optouse por utilizar também a proposta de Goldenberg et al. (2012b) que reagrupam Cambessedesia, Behuria Cham. e Huberia DC. juntamente com Dolichoura Brade e Merianthera Kuhlm., formando o clado Merianthera, um grupo monofilético. Ainda seguindo estes autores, a tribo Merianieae passa a ser delimitada pelos gêneros Graffenrieda DC, Salpinga DC, Meriania Sw. e Macrocentrum Hook.f., formando um agrupamento polifilético.

Para este estudo foram analisados espécimes do clado Merianthera e das tribos Merianieae e Microlicieae depositados na coleção do Herbário Leopoldo Krieger (CESJ), da Universidade Federal de Juiz de Fora, obtidos através de coletas esporádicas do projeto "Flora da Serra Negra" realizadas entre 2003 e 2012 e complementados por exemplares provenientes de coletas mensais específicas para Melastomataceae durante janeiro de 2014 até fevereiro de 2015. O material coletado foi herborizado e acondicionado de acordo com a metodologia usual de trabalhos taxonômicos e depositado na coleção do Herbário CESJ. Quando necessário, foi utilizado material adicional para a complementação das descrições. A descrição feita para o gênero Trembleya foi baseada nas características morfológicas dos táxons encontrados na Serra Negra. As identificações das espécies foram realizadas através de consultas à literatura especializada, coleções depositadas no Herbário CESJ e auxílio de especialistas.

Para as descrições morfológicas foram utilizados os conceitos de Radford (1986) Harris \& Harris (2001), Gonçalves \& Lorenzi (2007), além de Baumgratz (1985), para os frutos e sementes.

\section{Resultados e Discussão}

Melastomataceae Juss.

Árvores, arvoretas, arbustos, subarbustos e ervas, raro lianas ou epífitas. Indumento variado nas partes vegetativas e florais. Folhas simples, decussadas, sésseis, subsésseis ou pecioladas, com nervuras acródromas basais ou suprabasais, domácias presentes ou não. Inflorescências variadas, terminais ou axilares, brácteas e bractéolas geralmente presentes. Flores hermafroditas, períginas ou epígenas. Hipanto persistente, raro ausente na frutificação (Bertolonia); zona do disco glabra ou pilosa. Cálice de prefloração regular ou irregularmente valvar, persistente ou caduco. Corola de prefloração torcida, pétalas de cor variada. Estames usualmente em número igual ao dobro das pétalas (raro em número maior ou menor), dispostos em dois ciclos, isomórficos ou dimórficos na forma e/ou tamanho, anteras retilíneas, curvas a falciformes, poricidas, raro rimosas, conectivo prolongado ou não, raro com glândula dorsal, apendiculado ventral ou dorsalmente ou inapendiculado. Ovário súpero, semi-ínfero ou ínfero, (1)2-6(8-10)-locular, usualmente multiovulados, placentação axilar (raro basal). Frutos carnosos (bacídios ou bacáceos) ou secos (cápsulas loculicidas, ruptídios, bertolonídios ou velatídios), polispérmicos ou oligospérmicos. Sementes obtriangulares, obovadas ou cocleares, raro aladas (Baumgratz et al. 2007; Martins 2009a).

O clado Merianthera e as tribos Merianieae e Microlicieae na Serra Negra

Os grupos na Serra Negra estão representados por dez espécies. O clado Merianthera apresenta três espécies, Behuria parvifolia Cogn., Huberia nettoana Brade e Cambessedesia hilariana (Khunt.) DC., e as tribos Merianieae e Microlicieae estão representadas, respectivamente por Meriania claussenii (Naudin) Triana, pertencente à primeira tribo, e Lavoisiera imbricata (Thunb.) DC., Microlicia serpyllifolia D. Don, Rhynchanthera dichotoma (Desr.) DC., Trembleya elegans (Cogn.) Almeda \& A.B. Martins, T. parviflora (D. Don) Cogn. e T. phlogiformis DC. As espécies Behuria parvifolia, C. hilariana, H. nettoana, L. imbricata, $T$. elegans e $T$. phlogiformis são exclusivas dos campos rupestres, ocorrendo em altitudes acima de $1300 \mathrm{~m}$, em solos rasos, sob constante 
exposição solar. Já $M$. claussenii é a única com distribuição restrita ao interior de florestas de altitude, ambientes com umidade elevada, situados acima de $1100 \mathrm{~m}$. Rhynchanthera dichotoma foi encontrada somente em áreas antropizadas, crescendo em locais brejosos na beira de estrada. Enquanto Trembleya parviflora foi o táxon com maior distribuição nos ambientes, ocorrendo desde locais como pastagens e campos rupestres até o interior de florestas.

Em relação à extensão de ocorrência, Rhynchanthera dichotoma é o táxon com distribuição mais ampla, encontrado desde o norte da América do Sul, passando pelo Peru e por quase todo o território brasileiro, ocorrendo na Floresta Amazônica, Cerrado e Floresta Atlântica (BFG 2015; Martins 2009d). Cambessedesia hilariana, L. imbricata, T. parviflora e T. phlogiformis também estão amplamente distribuídas pelo território brasileiro, sendo encontradas principalmente em campos rupestres, cerrados e campos de altitude (Martins 2009; BFG 2015). Dentre as espécies de Microlicieae encontradas na Serra Negra, Trembleya elegans é a única que apresenta distribuição mais restrita, ocorrendo apenas nos cerrados e campos rupestres de Minas Gerais, Distrito Federal e Goiás (Matsumoto \& Martins 2005; BFG 2015).

Os táxons $B$. parvifolia, $H$. nettoana e $M$. claussenii apresentam endemismo regional, com distribuição restrita ao Sudeste do Brasil. Ocorrem apenas em ambientes associados à Floresta Atlântica, principalmente nas florestas ombrófilas e nos campos de altitude (BFG 2015). Behuria parvifolia e $M$. claussenii são consideradas na categoria "Vulnerável" para os estados de São Paulo e Rio de Janeiro, respectivamente (Chiavegatto \& Baumgratz 2008; Baumgratz 2009a), enquanto $H$. nettoana foi considerada como "Quase Ameaçada" por BFG (2015). No entanto, apesar das indicações supracitadas, nenhuma das três espécies foi tratada no Livro Vermelho da Flora do Brasil (Baumgratz et al. 2013). Portanto, é clara a necessidade de ampliação dos dados disponíveis sobre a situação da conservação de Melastomataceae no Brasil, a fim de avaliar detalhadamente a situação dos representantes da família, uma vez que, possivelmente, outros táxons estejam ameaçados de alguma forma e possam ser avaliados em atualizações das listas vermelhas.

A diversidade de espécies do clado Merianthera e das tribos Merianieae e Microlicieae na Serra Negra se mostrou muito próxima com a encontrada no Parque Estadual do Ibitipoca (PEI), com um total de sete espécies em comum. Embora o número de representantes de Microlicieae seja maior no PEI, com um total de nove espécies, Merianieae e o clado Merianthera na Serra Negra somam quatro espécies, o mesmo valor obtido para o PEI (Chiavegatto \& Baumgratz 2007; Barberena et al. 2010). Essa similaridade entre as áreas pode estar relacionada com a localização de ambas dentro de um mesmo complexo montanhoso. A Serra da Mantiqueira possui refúgios ecológicos que apresentam um complexo padrão de fitofisionomias, resultando em uma riqueza expressiva de espécies exclusivas para os altos das serras ou até mesmo endêmicas (OliveiraFilho et al. 2013). Além disso, fatores como altitude e topografia diferenciadas para área do Ibitipoca se sobressaem nas regiões vizinhas, incluindo a Serra Negra, originando um clima singular para ambas as áreas (Rocha 2013). Outra localidade inserida também no complexo da Mantiqueira é o Parque Estadual da Serra do Brigadeiro (PESB). A tribo Microlicieae está representada por quatro espécies no PESB, sendo apenas $T$. parviflora e T. phlogiformis, espécies com ampla distribuição (BFG 2015), compartilhadas com a Serra Negra. Já em relação ao clado Merianthera e à tribo Merianieae, o PESB compartilha com a área em estudo as espécies $B$. parvifolia e $M$. claussenii. A similaridade de espécies encontrada para estes dois grupos em ambas as áreas pode estar relacionada com a vegetação local. Pertencente ao Complexo Atlântico, o ambiente é úmido e marcado pela presença constante de neblina, sendo composto principalmente pela Floresta Estacional Semidecidual Montana e os campos de altitude (Leoni \& Tinte 2004).

As áreas com predomínio dos campos rupestres como Parque Nacional da Serra do Cipó, Parque Nacional da Serra da Canastra e Parque Estadual do Itacolomi possuem respectivamente 47, 33 e 31 representantes de Microlicieae (Semir et al. 1987; Romero \& Martins 2002; Rolim 2011). As três áreas compartilham quatro espécies da tribo com a Serra Negra, sendo elas, Lavoisiera imbricata, Microlicia serpyllifolia, Trembleya parviflora e T. phlogiformis. Diferentemente dos táxons de Microlicieae que apresentam um alto grau de endemismo para o domínio do Cerrado (Fritsch et al. 2004), estas quatro espécies não apresentam elevada especificidade de habitat, ocorrendo não apenas no Cerrado, mas também em ambientes inseridos na Floresta Atlântica (BFG 2015), como no caso, a Serra Negra. 


\section{Chave de identificação para as espécies do clado Merianthera e das tribos Merianieae e Microlicieae na Serra Negra}

1. Estames com apêndices dorsais calcarados, linear-subulados ou capitado-bilobados, anteras de ápice atenuado, não rostrado, sementes com testa áspera, granulosa ou rugosa.

2. Arbustos ou subarbustos; lacínias triangulares.

3. Folhas com 5 nervuras acródromas, de desenvolvimento perfeito, flores 6- meras; pétalas alvas; ovário setuloso-glanduloso .... 1. Behuria parvifolia

3'. Folhas com 3 nervuras acródromas, de desenvolvimento imperfeito; flores 5-meras; pétalas 1/2-inferior amarelo e 1/2-superior vermelho a alaranjado; ovário glabro .....

2. Cambessedesia hilariana

2'. Arvoretas ou árvores; lacínias estreito-triangulares ou reduzidas a uma bainha sinuosa.

4. Folhas papiráceas, face abaxial da lâmina providas de domácias marsupiformes; flores 4-meras; pétalas com ápice agudo; ovário súpero..... 3. Huberia nettoana

4'. Folhas cartáceas, face abaxial da lâmina desprovidas de domácias; flores 5-meras; pétalas com ápice truncado; ovário 1/3-ínfero 5. Meriania claussenii

1'. Estames com apêndices ventrais bilobados, espatulados ou inconspícuo-lobulados, anteras com ápice rostrado (rostro $0,5-2,5 \mathrm{~mm}$ compr.), sementes com testa foveolada.

5. Anteras com ápice longo-rostrado (rostro ca. $2,5 \mathrm{~mm}$ compr.); pétalas roxas, estaminódios presentes 7. Rhynchanthera dichotoma

5'. Anteras com ápice curto-rostrado (rostro ca. $0,5 \mathrm{~mm}$ compr); pétalas alvas, magenta ou róseas, estaminódios ausentes.

6. Folhas com base aguda a arredondada ou atenuada; bractéolas presentes (Trembleya).

7. Folhas com base atenuada, margem serreado-estrigosa, flores 6-meras, solitárias

8.1. Trembleya elegans

7'. Folhas com base aguda ou arredondada, margem inteira ou serrulada; flores 5-meras, organizadas em dicásios simples ou compostos.

8. Folhas com margem inteira, revoluta; indumento da face abaxial glandulosopontuado; cápsula loculicida 8.2. Trembleya parviflora

8'. Folhas com margem serrulada, plana; indumento de ambas as faces setulosoglanduloso; ruptídios 8.3. Trembleya phlogiformis

6'. Folhas com base obtusa ou truncada; bractéolas ausentes.

9. Folhas imbricadas; flores 6-meras, pétalas róseas; frutos deiscentes da base para o ápice

4. Lavoisiera imbricata

9'. Folhas não imbricadas, flores 5-meras, pétalas magentas; frutos deiscentes do ápice para a base. 6. Microlicia serpyllifolia

\section{Descrição dos táxons}

1. Behuria parvifolia Cogn., Fl. bras. 14(4): 12. 1886.

Fig.1a-g.

Arbustos ca. 0,6 m alt. Indumento setulosoglanduloso e setoso nos ramos, hipanto e lacínias do cálice, tricomas caducos ou não, pubescenteglanduloso na face abaxial das folhas. Folhas cartáceas, não imbricadas; pecíolo $1-5 \mathrm{~mm}$ compr.; lâmina 1-3×0,9-2,3 cm, ovada a raramente elíptica, base subcordada a arredondada, ápice obtuso, margem serreada, plana, 5 nervuras acródromas, 1-2 mm compr. suprabasais, de desenvolvimento perfeito, domácias marsupiformes, axilarprimárias, na face abaxial. Dicásios compostos
1-1,5 cm compr.; brácteas $5-7 \times$ ca. $3 \mathrm{~mm}$, elípticas, persistentes; bractéolas caducas, não vistas. Flores 6-meras; pedicelo ca. $10 \mathrm{~mm}$ compr.; hipanto 4-5 × 3-4 mm, campanulado, zona do disco glabra; cálice persistente; lacínias $2-3 \times$ ca. $1 \mathrm{~mm}$, triangulares; pétalas $10-11 \times 2-3 \mathrm{~mm}$, alvas, ovadas, ápice agudo; estames 12, isomórficos, anteras amarelas, ápice atenuado, não rostrado, conectivo inconspicuamente prolongado, apêndices ca. $3 \mathrm{~mm}$ compr., dorsais, linear-subulados, antessépalos com filetes ca. $7 \mathrm{~mm}$ compr., anteras ca. $4 \mathrm{~mm}$ compr., antepétalos com filetes ca. 5 mm compr., anteras 4-5 mm compr., estaminódios ausentes; ovário ca. 3,5 × $1 \mathrm{~mm}$, súpero, setuloso- 


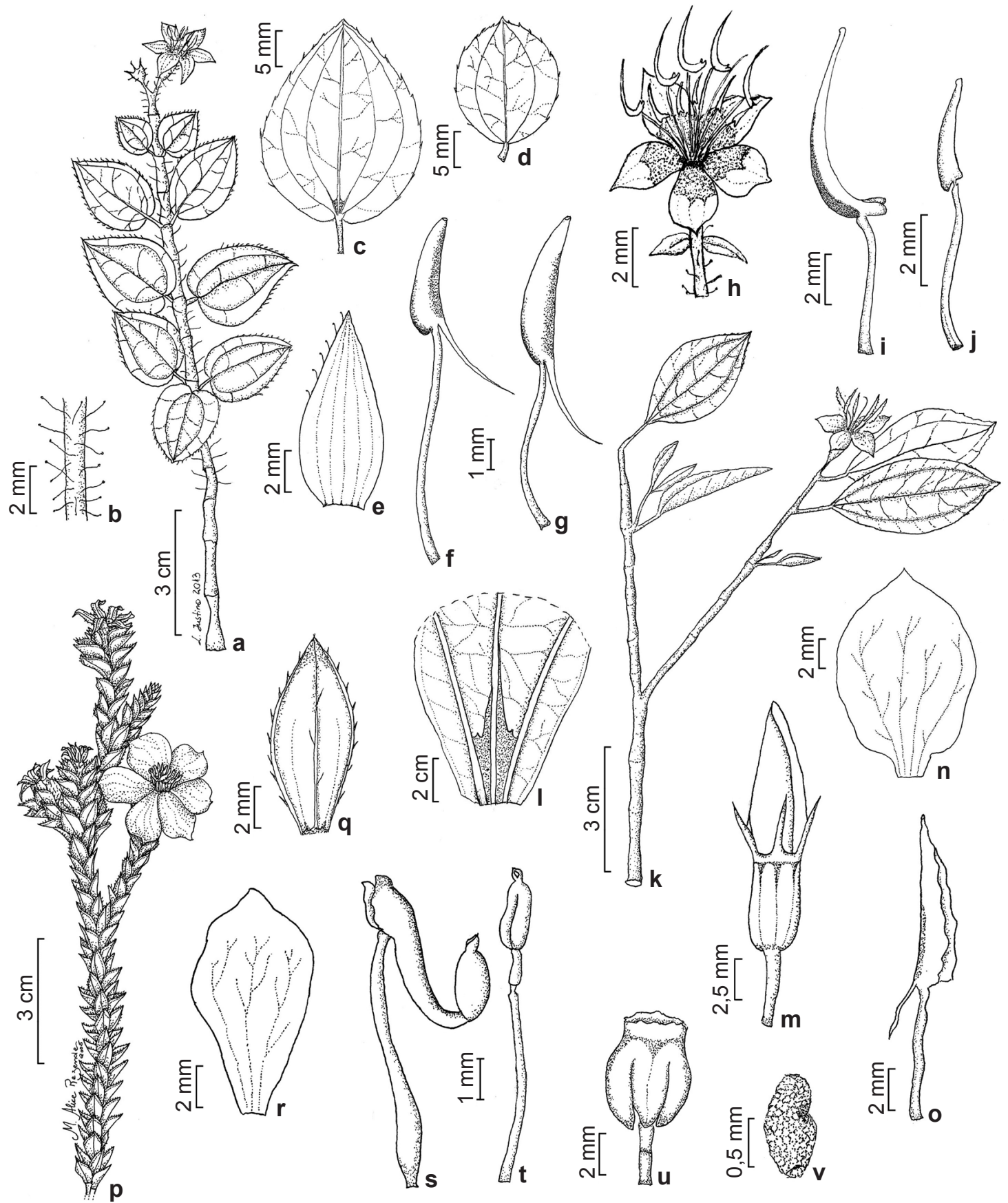

Figura 1 - a-g. Behuria parvifolia - a. ramo florífero; b. detalhe do indumento do ramo; c-d. folha (face abaxial); e. pétala; f. estame antessépalo; g. estame antepétalo. h-j. Cambessedesia hilariana - h. flor; i. estame antessépalo; j. estame antepétalo. k-o. Huberia nettoana - k. ramo florífero; 1. detalhe das domácias marsupiformes na face abaxial da folha; m. botão floral; n. pétala; o. estame antepétalo. p-v. Lavoisiera imbricata - p. ramo florífero; q. folha; r. pétala; s. estame antessépalo; t. estame antepétalo; u. fruto; v. semente. (a-g R.J.V. Alves \& N.L. Abreu 8769; h-j L.L. Justino et al. 49; k-o C.N. Matozinhos \& N.L. Abreu 428; p B. Chiavegatto et al. 96; q-v D.R. Gonzaga et al. 25). Figure 1 - a-g. Behuria pavifolia - a. floriferous branch; b. detail of branch indument; c-d. leaf (abaxial face); e. petal; f. antesepalous stamen; g. antepetalous stamen. h-j. Cambessedesia hilariana - h. flower; i. antesepalous stamen; j. antepetalous stamen. k-o. Huberia netoanna - k. floriferous branch; l. detail of marsupiform domatium; m. floral bud; n. petal; o. antepetalous stamen. p-v. Lavoisiera imbricata - p. floriferous branch; q. leaf; r. petal; s. antesepalous stamen; t. antepetalous stamen; u. fruit; v. seed. (a-g R.J.V.Alves \& N.L. Abreu 8769; h-j L.L. Justino et al. 49; k-o C.N. Matozinhos \& N.L. Abreu 428; p B. Chiavegatto et al. 96; q-v D.R. Gonzaga et al. 25). 
glanduloso, estilete ca. $15 \mathrm{~mm}$ compr., glabro. Velatídios 5-6 × 5-7 mm; sementes 2,5-3 × 1-1,5 mm, obpiramidais, testa áspera.

Material examinado: Rio Preto, IX.2011, fl. e fr., R.J.V. Alves \& N.L. Abreu 8769 (CESJ, R).

Behuria parviflora é endêmica do Brasil, ocorrendo em Minas Gerais, Rio de Janeiro e São Paulo em floresta ombrófila mista aluvial e campos de altitude na Floresta Atlântica a ca. $1.700 \mathrm{~m}$ de altitude (Baumgratz 2009a). Na Serra Negra, foi coletada em campo rupestre a ca. $1.590 \mathrm{~m}$ de altitude. Behuria parvifolia pode ser reconhecida pelas folhas coriáceas, ovadas, de base subcordada ou arredondada e flores 6-meras. Barberena et al. (2008), ao estudarem as Melastomataceae do Parque Nacional do Itatiaia, citam que as folhas de $B$. parvifolia não apresentam domácias, porém estas estruturas foram observadas em algumas folhas do único exemplar coletado na Serra Negra. A existência de poucos registros nos estados de Rio de Janeiro e São Paulo foi destacada por Chiavegatto \& Baumgratz (2008) e Baumgratz (2009a), fato que também ocorre no estado de Minas Gerais, com coletas conhecidas na Serra Negra e nos parques estaduais do Ibitipoca e Brigadeiro (Leoni \& Tinte 2004; Barberena et al. 2008).

\section{Cambessedesia hilariana (Kunth.) DC., Prod.} 3: 111.1828. Fig. 1h-j

Subarbustos $0,2-1,5 \mathrm{~m}$ alt. Indumento dos ramos, face abaxial das folhas, inflorescências, pedicelo, hipanto e lacínias do cálice, muito esparsamente setuloso-glanduloso, às vezes ausente. Folhas membranáceas, não imbricadas, sésseis ou pecioladas; pecíolo ca. $4 \mathrm{~mm}$ compr.; lâmina 3-15 × 1-6 mm, elíptica, ovada ou lanceolada, base agudo-atenuada a arredondada, ápice agudo, margem inteira ou denteada, plana, face adaxial glabra, 3 nervuras acródromas basais, de desenvolvimento imperfeito, domácias ausentes. Dicásios simples 2-3 cm compr. ou flores solitárias; brácteas ausentes; bractéolas 2-5 $\times 1-2 \mathrm{~mm}$, ovadas ou elípticas, persistentes. Flores 5-meras; pedicelo ca. $1 \mathrm{~mm}$ compr.; hipanto $3-5 \times$ 2-3 mm, campanulado, zona do disco glabra; cálice persistente; lacínias $1-1,5 \times$ ca. $1 \mathrm{~mm}$, triangulares; pétalas $5-8 \times 3-5 \mathrm{~mm}$, bicolores, metade inferior amarelo e metade superior vermelho a alaranjado, elípticas, oblongas ou obovadas, ápice agudo; estames 10, subisomórficos, anteras amarelas, com ápice atenuado, não rostrado, apêndices dorsais, calcarados, antessépalos, com filetes 5-8 $\mathrm{mm}$ compr., anteras 5-8 $\mathrm{mm}$ compr., conectivo prolongado $2-5 \mathrm{~mm}$ compr., antepétalos com filetes 4-6 $\mathrm{mm}$ compr., anteras 2,5-4 mm compr., conectivo prolongado 2,5-3 mm compr., estaminódios ausentes; ovário 3-4 $\times$ 2-3 mm, súpero, glabro, estilete 12-16 mm compr., pubescente-glanduloso na base. Cápsulas loculicidas 4-6 × 2-4 mm, deiscentes do ápice para a base; sementes ca. $0,5 \times 0,5 \mathrm{~mm}$, obpiramidais, testa granulosa.

Material examinado: Rio Preto, 22.II.2004, fl., $K$. Antunes et al. 5 (CESJ, RB); Lima Duarte, 11.V.2008, fl. e fr., N.L. Abreu \& L. Menini Neto 231 (CESJ); Olaria, 7.VI.2014, fl. e fr., L.L. Justino et al. 49 (CESJ); 7.VI.2014, fr., L.L. Justino et al. 58 (CESJ); 25.II.2015, fl. e fr., L.L. Justino et al. 136 (CESJ, UPCB).

Cambessedesia hilariana é endêmica do Brasil, ocorrendo no Tocantins, Bahia, Pernambuco, Piauí, Distrito Federal, Goiás, Espírito Santo, Minas Gerais, Rio de Janeiro (BFG 2015). A espécie é encontrada no Cerrado e na Floresta Atlântica, em formações rupestres, campos úmidos e áreas de cerrado (Martins 2009b; BFG 2015). $\mathrm{Na}$ Serra Negra, foi coletada em campo rupestre com solo quartzítico, sob alta incidência solar. Muitas vezes os indivíduos ocorrem em ambientes antropizados, marcados pela presença de gado e gramíneas invasoras. Cambessedesia hilariana pode ser caracterizada pelas folhas opostas fasciculadas e pétalas bicolores, com a metade superior vermelha a alaranjada e a metade inferior amarela. Diferentemente dos demais representantes de Microlicieae, Cambessedesia apresenta estames distintos apenas no tamanho, com conectivo espessado no dorso e anteras lineares a subuladas, nunca rostradas (Rodrigues 2009). Tais observações foram confirmadas no estudo de Fritsch et al. (2004) e o gênero foi retirado da tribo Microlicieae, ficando como parte de uma politomia não resolvida de um clado contendo várias outras espécies de Melastomataceae. Dessa forma, no presente trabalho optou-se por seguir a classificação proposta por Renner (1993) com alterações de Goldenberg et al. (2012b), tratando o gênero Cambessedesia como grupo-irmão de Behuria, Huberia, Dolichoura e Merianthera, formando o clado Merianthera. A explicação para inserção de Cambessedesia ao clado ainda é complexa, uma vez que o gênero é morfologicamente distinto dos demais representantes do grupo, além de apresentar sua maior diversidade em áreas secas de campo rupestre (Rodrigues 2009; Goldenberg et al. 2012b). 
3. Huberia nettoana Brade, Arq. Inst. Biol. Veg. 2(1): 13.1935.

Fig. 1k-o

Arvoretas a árvores 2,5-6 $\mathrm{m}$ alt. Indumento dos ramos jovens, folhas, hipanto e lacínias do cálice, furfuráceo-glanduloso, e nas regiões interaxilares, viloso-glanduloso. Folhas papiráceas, não imbricadas; pecíolo 5-15 mm compr.; lâmina $4,5-7,5 \times 1,2-3 \mathrm{~cm}$, elíptica a oblonga, base agudo-decorrente, ápice agudo, margem metade superior serreada, plana, 3 nervuras acródromas, 2-3 mm suprabasais, de desenvolvimento perfeito, domácias marsupiformes, axilar-primárias na face abaxial. Cimoides corimbosos 5-7 cm compr.; brácteas 20-23 ×9-11 mm, elípticas, persistentes; bractéolas caducas, não vistas. Flores 4-meras; pedicelo 5-10 $\mathrm{mm}$ compr.; hipanto $6-8 \times 2-4$ $\mathrm{mm}$, campanulado, zona do disco glabra; cálice persistente; lacínias 5-8 $\times$ ca. $0,5 \mathrm{~mm}$, estreitotriangulares; pétalas $12-15 \times 6-10 \mathrm{~mm}$, alvas, ovadas a assimétricas, ápice agudo; estames 8 , isomórficos, anteras amarelas, com ápice atenuado, não rostrado, conectivo não prolongado, apêndices 2-3 mm compr., dorsais, linear-subulados, antessépalos com filetes $6-8 \mathrm{~mm}$ compr., anteras 7-9 mm compr., antepétalos com filetes 5-7 mm compr., anteras 6-7 mm compr., estaminódios ausentes; ovário 4-5 × 2-2,5 mm, súpero, glabro; estilete ca. $15 \mathrm{~mm}$ compr., glabro. Ruptídios 8-10 $\times 7-8 \mathrm{~mm}$; sementes 5-6 × 0,5-1 mm, lineares, achatadas dorso-ventralmente, aladas, testa reticulada.

Material examinado: Rio Preto, 9.XI.2005, fl., C.N. Matozinhos et al. 239 (CESJ, UPCB); 10.XII.2008, fl., C.N. Matozinhos \& N.L. Abreu 428 (CESJ, HUFU); 23.XI.2014, fl., L.L. Justino et al. 119 (CESJ, HUFU, UPCB); 25.II.2015, fr., L.L. Justino et al. 140 (CESJ,UPCB).

Huberia nettoana é endêmica do Brasil, ocorrendo em Minas Gerais, Rio de Janeiro e São Paulo, em floresta ombrófila densa montana e alto-montana, entre $1.400-1.700 \mathrm{~m}$ de altitude, nas serras dos Órgãos, da Bocaina e da Mantiqueira e no maciço do Itatiaia (Baumgratz 2009b; BFG 2015). Na Serra Negra, foi encontrada em campo rupestre entre 1.200 e $1.600 \mathrm{~m}$ de altitude. Huberia nettoana pode ser diferenciada das demais espécies do clado Merianthera pelo hipanto 8-costado, lacínias estreito-triangulares, flores 4-meras e sementes lineares, aladas. Barberena et al. (2008) descreveram o ovário quase totalmente adnato ao hipanto, entretanto, nos espécimes coletados na Serra Negra, foi possível observar que o ovário é totalmente livre no hipanto. Segundo BFG (2015), H. nettoana está enquadrada como
"Quase Ameaçada". Tal fato provavelmente está relacionado à distribuição restrita ao Sudeste do país, associado com perda de habitat gerada pela ação antrópica nessa região (observação pessoal).

4. Lavoisiera imbricata (Thunb.) DC., Prodr. 3: 103. 1828.

Fig. 1p-v

Subarbustos $0,5-0,6 \mathrm{~m}$ alt. Ramos com esparsos tricomas setuloso-glandulosos nas regiões intra-axilares. Folhas cartáceas, imbricadas, sésseis; lâmina $5-10 \times 3-5 \mathrm{~mm}$, elíptica, base truncada, ápice agudo, margem serreado-estrigosa, plana, face adaxial glabra, face abaxial com nervura central recoberta por tricomas estrigosos; 3 nervuras acródromas basais, de desenvolvimento imperfeito, domácias ausentes; brácteas e bractéolas ausentes. Flores 6-meras, solitárias, sésseis; hipanto 3-4 $\times$ ca. $3 \mathrm{~mm}$, urceolado, zona do disco glabra; cálice persistente; lacínias ca. $3 \times 1-2 \mathrm{~mm}$, triangulares; pétalas 10-19 $\times 5-8 \mathrm{~mm}$, rosa, obovadas, ápice truncado; estames 12, dimórficos, anteras com ápice curto-rostrado, rostro ca. $0,5 \mathrm{~mm}$ compr., antessépalos com filetes 4-6 mm compr., anteras 2,2-2,5 mm compr., magenta, conectivo prolongado ca. $4 \mathrm{~mm}$ compr., apêndices ventrais, bilobados, antepétalos com filetes $4-5 \mathrm{~mm}$ compr., anteras 2-2,5 $\mathrm{mm}$ compr., amarelas, conectivo prolongado $1-1,5 \mathrm{~mm}$ compr., apêndices ventrais, espatulados, estaminódios ausentes; ovário ca. 3 $\times 3 \mathrm{~mm}$, ínfero, glabro; estilete ca. $5 \mathrm{~mm}$ compr., glabro. Ruptídios 3-6 × 3-4 mm, deiscentes da base para o ápice; sementes $0,5-1 \times$ ca. $0,25 \mathrm{~mm}$, ovado-oblongas, testa foveolada.

Material examinado: Rio Preto, 22.IV.2005, fl. e fr., A. Valente et al. 302 (CESJ, RB, UPCB); 21.I.2006, fl., T. Mota et al. 10 (CESJ, RB, UPCB); 21.X.2012, fl. e fr., D.R. Gonzaga et al. 25 (CESJ); 16.VII.2014, fl. e fr., L.L. Justino et al. 80 (CESJ).

Material adicional: MINAS GERAIS. Lima Duarte, Parque Estadual do Ibitipoca, Janela do Céu, 16.VI.2004, fl. e fr., B. Chiavegatto et al. 96 (RB).

Lavoisiera imbricata é endêmica do Brasil, ocorrendo na Bahia, Distrito Federal, Goiás, Espírito Santo, Minas Gerais, Rio de Janeiro, São Paulo e Paraná (BFG 2015). É encontrada em campos rupestres, campos graminosos sazonalmente alagados, bordas de mata de galeria, áreas perturbadas e campos úmidos entre 600 e $1.800 \mathrm{~m}$ de altitude (Martins et al. 2009). Na Serra Negra, foi coletada em regiões sob alta incidência de luz solar onde predominam os campos rupestres com solos rasos, arenosos, encharcados sazonalmente. A presença de cápsula com deiscência basal é uma característica única do gênero Lavoisiera DC., 
sendo bastante utilizada para distingui-lo dos demais representantes de Microlicieae, principalmente do gênero Microlicia, do qual é muito próximo (Martins 2009c). Na flora fanerogâmica da Serra Negra, esta espécie foi citada como Lavoisiera compta DC. (Salimena et al. 2013), no entanto esse nome é considerado sinônimo de $L$. imbricata (BFG 2015). Em campo, a espécie é facilmente reconhecida por serem subarbustos arredondados de folhas sésseis e imbricadas e fruto deiscente da base para o ápice, quando maduro.

5. Meriania claussenii Triana, Trans. Linn. Soc. Bot. 28 : 66. 1871.

Fig. 2a-g

Árvores 15-16 m alt. Indumento das folhas e inflorescências esparsamente dendrítico-furfuráceo, tricomas muito cedo caducos. Folhas cartáceas, não imbricadas; pecíolo 12-34 mm compr.; lâmina 7,5-19,5 × 3-6,2 cm, elíptica, base aguda a cuneada, ápice agudo a acuminado, margem 1/2-3/4 serreada para o ápice, plana, 5 nervuras acródromas, $1-5 \mathrm{~mm}$ compr. suprabasais, de desenvolvimento perfeito, domácias ausentes. Tirsoides de umbela 7,5-9 cm compr; brácteas ca. $1 \times 0,5 \mathrm{~mm}$, estreito-elípticas, caducas; bractéolas ca. $0,1 \times 0,25 \mathrm{~mm}$, oblongas, caducas. Flores 5-meras; pedicelo 5-10 mm compr.; hipanto ca. $5 \times 5 \mathrm{~mm}$, campanulado, zona do disco glabra; cálice persistente; lacínias reduzidas a uma bainha sinuosa; pétalas $1,8-2 \times 0,7-1 \mathrm{~cm}$, alvas, obovadas, ápice truncado; estames 10 , dimórficos, anteras com ápice atenuado, não rostrado, apêndices dorsais, capitado-bilobados, antessépalos com filetes 7,5-10 mm compr., anteras 4-5 mm compr., alvas, conectivo com porção ascendente dos apêndices 2-3 mm compr., antepétalos com filetes 10-12 cm compr., anteras 3-4 mm compr., roxas, conectivo com porção ascendente dos apêndices 2,5-3 mm compr., estaminódios ausentes; ovário 2-3 × ca. $2 \mathrm{~mm}, 1 / 3$-ínfero, glabro; estilete ca. $10 \mathrm{~mm}$ compr., glabro. Velatídios 5-7 × 6-9 mm; sementes $1-1,5 \times$ ca. $1 \mathrm{~mm}$, obpiramidais, testa rugosa.

Material examinado: Lima Duarte, 15.VII.2009, b.f., J.A. Oliveira 55 (CESJ); Rio Preto, 27.VIII.2006, fl., A.S.M. Valente \& P.O. Garcia 491 (CESJ, UPCB).

Material adicional: RIO DE JANEIRO. Itatiaia, Parque Nacional do Itatiaia, 11.IX.2007, fr., J.F.A. Baumgratz et al. 1001 (CESJ, RB); Nova Friburgo, Macaé de Cima, Sítio Fazenda Velha, 19.VII.1990, fl., T. Fontoura 185 (ESA, FLOR, RB).

Meriania claussenii é endêmica do Brasil, restrita a Minas Gerais, Rio de Janeiro e São Paulo, ocorrendo em formações florestais, entre 800 e $1.100 \mathrm{~m}$ de altitude (Chiavegatto \&
Baumgratz 2008). Na Serra Negra, foi encontrada no interior da floresta nebular, em ambientes úmidos e sombreados. A espécie pode ser facilmente caracterizada pelas lacínias reduzidas a uma bainha sinuosa, apêndices dorsais capitado-bilobados e estames antepétalos com anteras roxas. Meriania claussenii é classificada como "Vulnerável" devido ao endemismo regional associado ao pequeno número de indivíduos por população (Chiavegatto \& Baumgratz 2008).

6. Microlicia serpyllifolia D.Don, Mem. Wern. Nat. Hist. Soc., 4: 302. 1823.

Fig. 2h-1

Subarbustos ca. $1 \mathrm{~m}$ alt. Indumento pubescente e glanduloso nos ramos, folhas, hipanto e lacínias do cálice. Folhas cartáceas, não imbricadas, sésseis; lâmina 2-5 × 1-3 mm, oblonga a elíptica, base obtusa, ápice obtuso, curto-apiculado, margem inteira, plana, 3 nervuras acródromas basais, de desenvolvimento imperfeito, a central evidente e as laterais inconspícuas, domácias ausentes; brácteas e bractéolas ausentes. Flores 5-meras, solitárias; pedicelo 1-3 mm compr.; hipanto, 3-4 × ca. 2 $\mathrm{mm}$, campanulado, zona do disco glabra; cálice persistente; lacínias 1-2 × 0,5-1 mm, triangulares; pétalas ca. $5 \times 3-4 \mathrm{~mm}$, magentas, obovadas, ápice obtuso; estames 10, dimórficos, anteras com ápice curto-rostrado, rostro ca. 0,5 mm compr., antessépalos com filetes ca. $3 \mathrm{~mm}$ compr., anteras ca. $2 \mathrm{~mm}$ compr., magenta, conectivo prolongado ca. $3 \mathrm{~mm}$ compr., apêndices ventrais, espatulados, antepétalos com filetes 2-3,5 mm compr., anteras 1-2 mm compr., amarelas, conectivo prolongado ca. $1 \mathrm{~mm}$ compr., apêndices ventrais, inconspícuolobulados, estaminódios ausentes; ovário ca. $2 \times$ $1 \mathrm{~mm}$, súpero, glabro; estilete ca. $10 \mathrm{~mm}$ compr., glabro. Cápsulas loculicidas 2,5-3 × ca. $2 \mathrm{~mm}$, deiscentes do ápice para a base; sementes ca. 0,4 $\times$ $0,4 \mathrm{~mm}$, ovoides, testa foveolada.

Material examinado: Rio Preto 2.II.2004, fl. e fr., K. Antunes et al. 3 (CESJ, HUFU, RB, UPCB ); 20.VIII.2004, fl. e fr., C.N. Matozinhos et al. 8 (CESJ); 26.VI.2008, fl. e fr., F.S. Souza et al. 525 (CESJ); 21.II.2008, fl. e fr., F.S. Souza et al. 335 (CESJ, HUFU). Material adicional: MINAS GERAIS. Lima Duarte, Parque Estadual do Ibitipoca, bifurcação Monjolinho e Ponte de Pedra, 15.VI.2004, fl. e fr., B. Chiavegatto et al. 82 (HUFU, RB).

Microlicia serpyllifolia é endêmica do Brasil e distribui-se pela Bahia, Distrito Federal, Goiás e Minas Gerais (BFG 2015). Ocorre nos campos rupestres arbustivos e em cerrado de altitude, em solos arenosos rasos, úmidos e com exposição direta do sol (Chiavegatto \& Baumgratz 2007). Na 


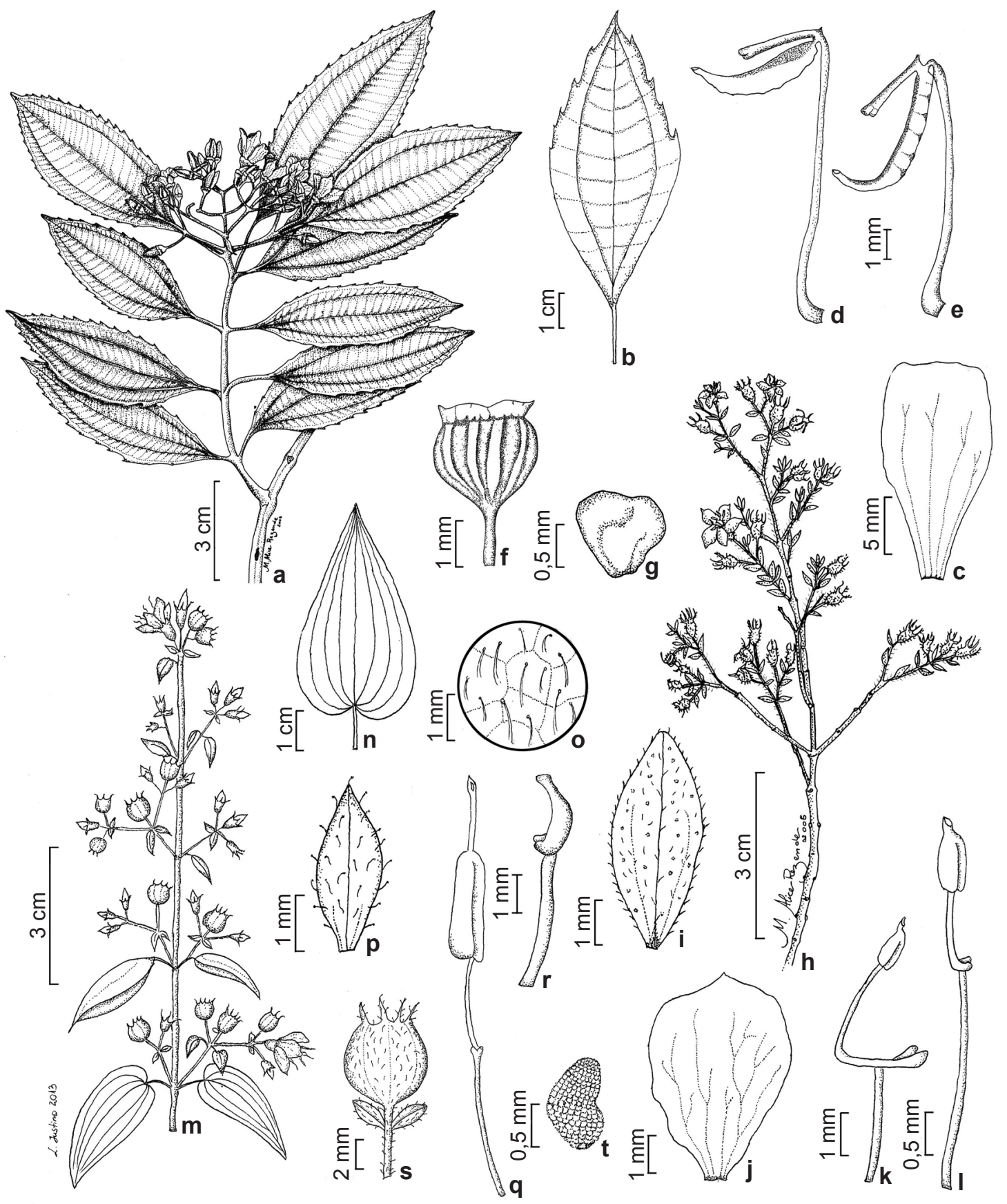

Figura 2 - a-g. Meriania claussenii - a. ramo florífero; b. folha (face adaxial); c. pétala; d. estame antepétalo; e. estame antessépalo; f. fruto; g. semente. h-1. Microlicia serpyllifolia - h. ramo florífero, i. folha (face adaxial); j. pétala; k. estame antessépalo; 1. estame antepétalo. m-t. Rynchanthera dichotoma - m. ramo florífero; $\mathrm{n}$. folha (face adaxial); o. detalhe do indumento das folhas; p. bractéola; q. estame antepétalo; r. estaminódio; s. fruto; t. semente. (a Fontoura 185; b-f J.A. Oliveira et al. 55; g J.F.A. Baumgratz et al. 1001; h B. Chiavegatto et al. 82; i-1 F.S. Souza et al. 335; m-t K. Antunes et al. 118).

Figure 2 - a-g. Meriania claussenii - a. floriferous branch; b. leaf (adaxial face); c. petal; d. antepetalous stamen; e. antesepalous stamen; f. fruit; g. seed. h-1. Microlicia serpyllifolia - h. floriferous branch; i. leaf (adaxial face); j. petal; k. antesepalous stamen; 1. antepetalous stamen. m-t. Rhynchanthera dichotoma - m. floriferous branch; $n$. leaf (adaxial face); o. detail of the indument; $\mathrm{p}$. bracteole; q. antesepalous stamen; $\mathrm{r}$. staminode; s. fruit; t. seed. (a Fontoura 185; b-f J.A. Oliveira et al. 55; g J.F.A. Baumgratz et al. 1001; h B. Chiavegatto et al. 82; i-1 F.S. Souza et al. 335; m-t K. Antunes et al. 118). 
Serra Negra, foi encontrada em áreas de pastagens e nos solos quartzíticos dos campos rupestres sob alta incidência solar. Na flora fanerogâmica da Serra Negra, esta espécie foi citada como Microlicia fulva (Spreng.) Cham. (Salimena et al. 2013), no entanto esse nome é considerado sinônimo de M. serpyllifolia (BFG 2015). A espécie pode ser facilmente reconhecida pelas folhas com tricomas glandulares pontuados juntamente com tricomas pubescentes diminutos.

7. Rhynchanthera dichotoma DC., Prodr. 3: 107. 1828.

Fig. $2 m-t$

Arbustos ca. 1,5 m alt. Indumento dos ramos, folhas, inflorescências, brácteas, bractéolas, hipanto e lacínias do cálice setuloso-glanduloso. Folhas cartáceas, não imbricadas; pecíolo 10-13 mm compr.; lâmina 4-4,5 × 2-3 cm, elíptica a ovada, base cordada, ápice agudo, margem levemente serrulada, plana, 7 nervuras acródromas basais, de desenvolvimento perfeito, domácias ausentes. Tirsoides em cimeiras distalmente bíparas 1-2,5 cm compr.; brácteas ca. $10 \times 2 \mathrm{~mm}$, lanceoladas a ovadas, persistentes; bractéolas 2,5-4 $\times 0,5-1 \mathrm{~mm}$, lanceoladas, persistentes. Flores 5-meras; pedicelo 1-3 mm compr.; hipanto ca. 7-2 mm compr., urceolado, zona do disco glabra; cálice persistente; lacínias $2-3 \times$ ca. 0,5 $\mathrm{mm}$, triangulares; pétalas $10-12 \times$ ca. $5 \mathrm{~mm}$, roxas, elípticas a oblongas, ápice acuminado; estames 5 , isomórficos, antessépalos com filetes ca. $4 \mathrm{~mm}$ compr., anteras ca. $6 \mathrm{~mm}$ compr., magenta, com ápice longo-rostrado, rostro ca. 2,5 $\mathrm{mm}$ compr., conectivo prolongado ca. $2 \mathrm{~mm}$ compr., apêndices ventrais, bilobados, estaminódios antepétalos; ovário ca. $2 \times 2 \mathrm{~mm}$, súpero, glabro; estilete 12-14 $\mathrm{mm}$ compr., glabro. Cápsulas loculicidas 5-8 $\times$ ca. $5 \mathrm{~mm}$, deiscentes do ápice para a base; sementes ca. $1 \times 1 \mathrm{~mm}$, reniformes, testa foveolada.

Material Examinado: Serra Negra, entre Conceição do Monte Alegre e Três Cruzes, 21.V.2004, fl. e fr., $K$. Antunes et al. 118 (CESJ, UPCB).

Rhynchanthera dichotoma apresenta ampla distribuição, sendo encontrada na Venezuela, Guiana, Guiana Francesa e Peru, e no Brasil, ocorre no Acre, Amazonas, Roraima, Bahia, Distrito Federal, Goiás, Mato Grosso do Sul, Espírito Santo, Minas Gerais, Rio de Janeiro, São Paulo, Paraná, Rio Grande do Sul e Santa Catarina (Martins 2009d; BFG 2015). Na Serra Negra, foi encontrada em ambiente antropizado de beira de estrada. Rynchanthera dichotoma pode ser reconhecida pelas folhas de base cordada, anteras de ápice longamente rostrado, além da presença de estaminódios.

Trembleya DC. Prodr. 3: 125. 1828.

Subarbustos ou arbustos. Folhas opostas, pecioladas ou sésseis, face adaxial com nervuras acródromas impressas, secundárias pouco evidentes, face abaxial com nervuras acródromas salientes, domácias ausentes. Inflorescências em dicásios, simples ou compostos, ou flores solitárias, terminais e/ou axilares. Flores 5-6-meras; zona do disco glabra; hipanto campanulado ou urceolado; cálice persistente; lacínias triangulares; pétalas obovadas, alvas ou róseas; estames 10 a 12, dimórficos, de dois tamanhos, anteras com ápice curto-rostrado, poro terminal, conectivo prolongado abaixo das tecas, apêndices ventrais, estaminódios ausentes; ovário 5(-6)-locular, súpero, glabro, estilete glabro, estigma punctiforme. Cápsulas loculicidas ou ruptídios, polispérmicos; sementes oblongas, curvas no ápice, testa foveolada.

8.1 Trembleya elegans (Cogn.) Almeda \& A.B.Martins, Novon 11: 6. $2001 . \quad$ Fig. 3a-e

Subarbustos a arbustos $0,5-1,5 \mathrm{~m}$ alt. Indumento dos ramos, face abaxial das folhas, hipanto e lacínias do cálice glanduloso e estrigoso. Folhas cartáceas, levemente imbricadas; sésseis ou pecioladas; pecíolo até $1 \mathrm{~mm}$ compr.; lâmina $0,6-1,7 \times 0,3-0,7 \mathrm{~cm}$, elíptica, base atenuada, ápice curtamente acuminado, margem serreadoestrigosa, plana, face adaxial glabra, 3 nervuras acródromas basais, de desenvolvimento imperfeito, face abaxial com nervura principal recoberta por tricomas estrigosos. Brácteas ausentes; bractéolas 3-4 × ca. $1 \mathrm{~mm}$, elípticas, caducas. Flores 6-meras, solitárias; pedicelo 3-7 mm compr.; hipanto 3-8 $\times 2-3 \mathrm{~mm}$, urceolado; lacínias $2-3 \times 1-1,5 \mathrm{~mm}$; pétalas $1-1,5 \times 0,4-0,7 \mathrm{~cm}$, róseas, obovadas, ápice truncado a assimétrico; estames 12 , anteras ca. 2 $\mathrm{mm}$ compr., magentas, rostro ca. $0,5 \mathrm{~mm}$ compr., apêndices bilobados, antessépalos com filetes 4-5 $\mathrm{mm}$ compr., conectivo prolongado $3-4 \mathrm{~mm}$ compr., antepétalos com filetes ca. $4 \mathrm{~mm}$ compr., conectivo prolongado ca. $1 \mathrm{~mm}$ compr.; ovário $2-3 \times 2-3$ $\mathrm{mm}$, estilete $3-5 \mathrm{~mm}$ compr. Cápsulas loculicidas $2-3 \times$ ca. $2 \mathrm{~mm}$, deiscentes do ápice para a base, sementes ca. $0,8 \times 0,3 \mathrm{~mm}$.

Material examinado: Rio Preto, 27.I.2007, fl., L. Menini Neto et al. 287 (CESJ, HUFU); 20.X.2012, fl., K. Antunes et al. 341 (CESJ); 16.VII.2014, fl., L.L. Justino et al. 79 (CESJ); 25.II.2015, fl. e fr., L.L. Justino et al. 135 (CESJ, HUFU, MBM, UPCB). 


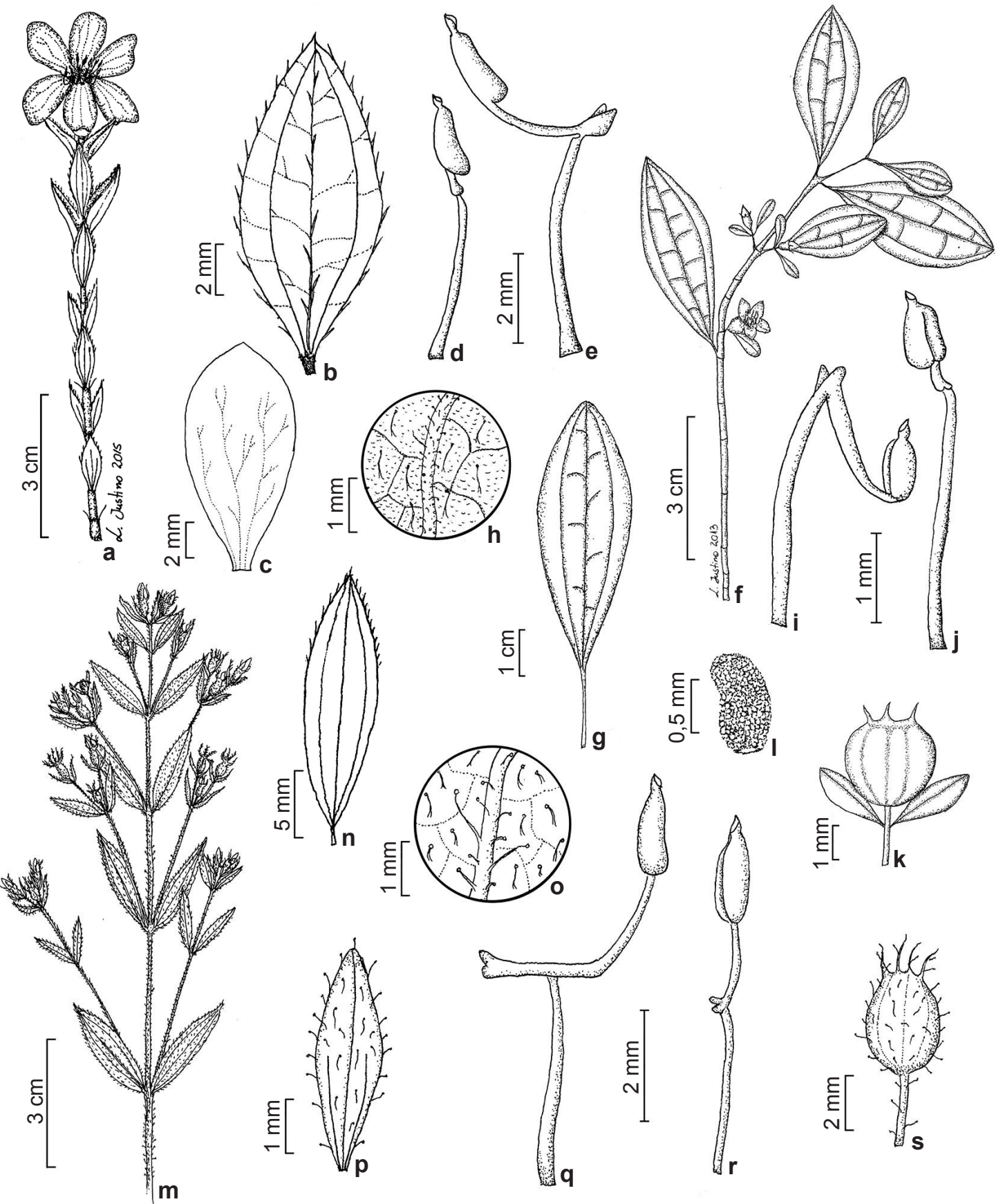

Figura 3 -a-e. Trembleya elegans - a. ramo florífero; b. folha (face abaxial); c. pétala; d. estame antepétalo; e. estame antessépalo. f-l. Trembleya parviflora - f. ramo florífero; g. folha (face adaxial); h. detalhe do indumento da face abaxial da folha; i. estame antessépalo; j. estame antepétalo; $\mathrm{k}$. fruto e bractéola; 1 . semente. $\mathrm{m}$-s. Trembleya phlogiformis - $\mathrm{m}$. ramo florífero; $\mathrm{n}$. folha (face adaxial); o. detalhe do indumento das folhas; p. bractéola; q. estame antessépalo; r. estame antepétalo; s. fruto. (a-e L. Menini Neto et al. 287; fJ.A. Oliveira et al. 75; g-1 F.S. Souza \& O.J. Bastos 513; m L. Krieger CESJ 14587; n-s K. Antunes et al. 82). Figure 3 - a-e. Trembleya elegans - a. floriferous branch; b. leaf (abaxial face); c. petal; d. antepetalous stamen; e. antesepalous stamen. f-1. Trembleya parviflora - f. floriferous branch; g. leaf (adaxial face); h. detail of the indument on abaxial face of the leaf; i. antesepalous stamen; j. antepetalous stamen; k. fruit and bracteole; 1. seed. m-s. Trembleya phlogiformis - m. floriferous branch; n. leaf (adaxial face); o. detail of leaf indument; p. bracteole; q. antesepalous stamen; r. antepetalous stamen; s. fruit. (a-e L. Menini Neto et al. 287; fJ.A. Oliveira et al. 75; g-1 F.S. Souza \& O.J. Bastos 513; $\mathrm{m}$ L. Krieger CESJ 14587; n-s K. Antunes et al. 82). 
Trembleya elegans é endêmica do Brasil, ocorrendo apenas em Goiás e Minas Gerais (Almeda \& Martins 2001; BFG 2015). Na Serra Negra, foi encontrada em campo rupestre, próximo ao curso d'água a ca. $1.600 \mathrm{~m}$ de altitude. Difere de T. parviflora e de T. phlogiformis principalmente pelas folhas subsésseis com margem serreadoestrigosa, flores 6-meras, solitárias.

8.2 Trembleya parviflora Cogn., Fl. bras. 14(3): 127. 1883.

Fig. 3f-1

Arbustos, 1,5-3 m alt. Indumento dos ramos, pecíolos, face abaxial das folhas, inflorescências, brácteas, bractéolas, hipanto e cálice pubescente e glanduloso-pontuado. Folhas papiráceas a cartáceas, não imbricadas; pecíolo $2-15 \mathrm{~mm}$ compr.; lâmina $1,3-7 \times 0,3-2,5 \mathrm{~cm}$, elíptica a oblonga, base aguda, ápice agudo a obtuso, margem inteira, revoluta, face adaxial glabra, 3 nervuras acródromas basais de desenvolvimento perfeito. Dicásios simples ou compostos, $1-2 \mathrm{~cm}$ compr.; brácteas 5-12 × 2-6 mm, espatuladas, persistentes; bractéolas $2-2,5 \times$ ca. $0,3 \mathrm{~mm}$, linear-obovadas, persistentes. Flores 5-meras; pedicelo 1-5 mm compr.; hipanto, 3,5-4 × 1,3-2 mm, campanulado; lacínias 1-1,5 × 1-1,2 mm; pétalas 5-10 × 3-7 mm, alvas ou róseas, obovadas, ápice obtuso; estames 10, anteras com rostro ca. $0,5 \mathrm{~mm}$ compr., antessépalos com filetes ca. $3 \mathrm{~mm}$ compr., anteras ca. 1-1,2 mm compr., magenta, conectivo prolongado ca. $2 \mathrm{~mm}$ compr., apêndices bilobados, antepétalos com filetes ca. 3-3,2 $\mathrm{mm}$ compr., anteras ca. $1 \mathrm{~mm}$ compr., amarelas, conectivo prolongado ca. $3 \mathrm{~mm}$ compr., apêndices espatulados; ovário $2-3 \times$ ca. $1 \mathrm{~mm}$, estilete ca. 3 $\mathrm{mm}$ compr. Cápsulas loculicidas $3-4 \times$ ca. $3 \mathrm{~mm}$, deiscentes do ápice para a base; sementes $0,5-0,4$ $\times$ ca. $0,25 \mathrm{~mm}$.

Material examinado: Lima Duarte, 25.X.2008, fl. e fr., D. Monteiro et al. 374 (CESJ); 16.VII.2009, fl. e fr., J.A. Oliveira et al. 75 (CESJ); 6.VI.2014, fl., L.L. Justino et al. 40 (CESJ); Olaria, 7.VI.2014, fl. e fr., L.L. Justino et al. 59 (CESJ); Rio Preto, 21.VIII.2004, fl. e fr., C.N. Matozinhos et al. 41 (CESJ, RB, UPCB); 25.IV.2005, fl., C.N. Matozinhos et al. 200 (CESJ, RB); 21.IV.2005, fl., C.N. Matozinhos et al. 224 (CESJ); 27.VII.2006, fl. e fr., C.N. Matozinhos et al. 301 (CESJ); 10.IV.2007, fl. e fr., N.L. Abreu et al. 174 (CESJ); 31.VI.2007, fl., F.R.G. Salimena \& P.H. Nobre 2480 (CESJ); 26.IV.2008, fl., F.S. Souza \& O.J. Bastos Neto 513 (CESJ, HUFU); 29.IX.2012, fl. e fr., L.L. Justino et al. 8 (CESJ); 29.VIII.2014, fl. e fr., L.L. Justino et al. 91 (CESJ, JABU); Santa Bárbara do Monte Verde, 6.VI.2014, fl., L.L. Justino et al. 36 (CESJ).
Trembleya parviflora é endêmica do Brasil, ocorrendo na Bahia, Distrito Federal, Goiás, Espírito Santo, Minas Gerais, Rio de Janeiro, São Paulo e Paraná (BFG 2015). Encontrada em campos rupestres, campos de altitude, cerrados e em florestas pluviais, sendo raramente coletada em Floresta Atlântica (Chiavegatto 2007; Martins 2009). Na Serra Negra, T. parviflora foi encontrada em campo rupestre, com solo quartzítico, sob alta incidência solar, em campos antropizados e também no interior de mata. A espécie é localmente conhecida como "candeinha do brejo" e forma populações dominantes em áreas de solo úmido. Trembleya parviflora pode ser diferenciada das demais espécies de Trembleya principalmente pelas folhas discolores de margem inteira revoluta.

8.3 Trembleya phlogiformis DC., Prodr. 3: 126. 1828.

Fig. $3 \mathrm{~m}-\mathrm{s}$

Arbustos ca. 0,5 m alt. Indumento dos ramos, folhas, inflorescências, brácteas, bractéolas, hipanto e lacínias do cálice setuloso-glanduloso. Folhas membranáceas, não imbricadas, sésseis ou pecioladas; pecíolo até $1 \mathrm{~mm}$ compr.; lâmina $2-3 \times 0,5-1 \mathrm{~cm}$, linear-elíptica, base aguda a arredondada, ápice agudo, margem serrulada, plana, 5 nervuras acródromas, 1-1,5 $\mathrm{mm}$ suprabasais, de desenvolvimento perfeito. Dicásio simples 7-11 cm compr.; brácteas 7-10 × 2-3 $\mathrm{mm}$, elípticas, persistentes; bractéolas 4-6 $\times 1-2$ $\mathrm{mm}$, elípticas, caducas. Flores 5-meras; pedicelo 1,5-3 mm compr.; hipanto 2,6-3,3 × 1-1,2 mm urceolado; lacínias 3-4 × 2-3 mm; pétalas 5-7 $\times 2-3 \mathrm{~mm}$, róseas, ápice agudo e acuminado; estames 10, anteras com rostro ca. $0,5 \mathrm{~mm}$ compr., conectivo prolongado ca. $2 \mathrm{~mm}$ compr., antessépalos com filetes ca. $4 \mathrm{~mm}$ compr., anteras ca. $2 \mathrm{~mm}$ compr., magenta, apêndices bilobados, antepétalos com filetes ca. $3 \mathrm{~mm}$ compr., anteras ca. $2 \mathrm{~mm}$ compr., amarelas, apêndices espatulados; ovário 3-4 × ca. $2 \mathrm{~mm}$, estilete ca. $5 \mathrm{~mm}$ compr. Ruptídios 4-5 × 2-4 mm, deiscentes do ápice para a base, sementes $0,4-0,5 \times$ ca. $0,3 \mathrm{~mm}$.

Material examinado: Rio Preto, 11.IV.2004, fl. e fr., $K$. Antunes et al. 82 (CESJ, RB, UPCB).

Trembleya phlogiformis é endêmica do Brasil, ocorrendo na Bahia, Distrito Federal, Goiás, Mato Grosso, Espírito Santo, Minas Gerais, Rio de Janeiro, São Paulo e Paraná (BFG 2015). Encontrada em formações rupestres, campos de altitude, cerrados e raramente na Floresta Atlântica (Chiavegatto 2007; Martins 2009). 
Na Serra Negra, foi coletada em campo rupestre arbustivo de solo quartzítico, sob exposição direta do sol. A espécie pode ser reconhecida principalmente pela presença de indumento setuloso-glanduloso, que lhe confere um aspecto pegajoso (Chiavegatto 2007). Folhas com margem serrulada com 5 nervuras acródromas e indumento setuloso-glanduloso são algumas características que diferenciam T. phlogifomis das demais espécies de Trembleya ocorrentes na Serra Negra.

\section{Agradecimentos}

À FAPEMIG, o auxílio financeiro nos processos CRA 1891/06, APQ 1810-5.02/07, APQ 03507-09. Ao CNPq, o apoio no processo 551462/2008-6. À PROPESQ/UFJF, a bolsa PROBIC concedida à primeira autora. Aos proprietários das RPPNs e das fazendas, a autorização para coletas e expedições. À ilustradora Maria Alice, as ilustrações dos hábitos de $L$. imbricata, M. claussenii, M. serpyllifolia e $T$. phlogiformis. Ao Dr. Ruy José Valka Alves, do Museu Nacional do Rio de Janeiro, a doação de material de B. parvifolia. Aos revisores anônimos e ao Dr. Renato Goldenberg, que contribuíram para melhorar a qualidade deste trabalho.

\section{Referências}

Abreu, N.L.; Menini Neto, L. \& Konno, T.U.P. 2011. Orchidaceae das Serras Negra e do Funil, Rio Preto, Minas Gerais, e similaridade florística entre formações campestres e florestais do Brasil. Acta Botanica Brasilica 25: 58-70.

Araújo, I.M. 2013. Melastomataceae no Parque Estadual do Biribiri, Diamantina, Minas Gerais, Brasil: tratamento sistemático e comparação florística. Dissertação de Mestrado. Universidade Federal de Uberlândia, Uberlândia. 128p.

Barberena, F.F.V.A.; Baumgratz, J.F.A. \& Chiavegatto, B. 2008. Melastomataceae no Parque Nacional do Itatiaia, sudeste do Brasil: Tribos Bertolonieae e Merianieae. Rodriguésia 59: 381-392.

Barberena, F.F.V.A.; Chiavegatto, B. \& Baumgratz, J.F.A. 2010. Melastomataceae nos remanescentes florestais do Parque Estadual do Ibitipoca, Minas Gerais, Brasil. Boletim de Botânica da Universidade de São Paulo 28: 141-157.

Baumgratz, J.F.A. 1985. Morfologia dos frutos e sementes de Melastomataceae brasileiras. Arquivos do Jardim Botânico do Rio Janeiro 27: 113-155.

Baumgratz, J.F.A. 2009a. Behuria Cham. In: Wanderley, M.G.L.; Shepherd, G.J.; Melhem, T.S.; Giulietti, A.M. \& Martins, S.E. (eds.). Flora fanerogâmica do estado de São Paulo. Instituto de Botânica, São Paulo. Vol. 6, pp. 8-10.
Baumgratz, J.F.A. 2009b. Huberia DC. In: Wanderley, M.G.L.; Shepherd, G.J.; Melhem, T.S.; Giulietti, A.M. \& Martins, S.E. (eds.). Flora fanerogâmica do estado de São Paulo. Instituto de Botânica, São Paulo. Vol. 6, pp. 26-29.

Baumgratz, J.F.A.; Pinheiro, F.M.; Filho, L.A.F.S.; Barros, F.S.; Sfair, J.C.; Moraes, M.A. \& Messima, T. 2013. Melastomataceae. In: Martinelli, G. \& Moraes, M.A. (orgs.). Livro vermelho da flora do Brasil. Instituto de Pesquisa do Jardim Botânico do Rio de Janeiro, Rio de Janeiro. Pp. 673-696.

Baumgratz, J.F.A.; Souza, M.L.D.R. \& Tavares, R.A.M. 2007. Melastomataceae na Reserva Ecológica de Macaé de Cima, Nova Firburgo, Rio de Janeiro, Brasil I - Tribos Bertolonieae, Merianieae e Microlicieae. Rodriguésia 58: 797-822.

Baumgratz, J.F.A. \& Souza, M.L.D.R. 2011. Melastomataceae na Reserva Ecológica de Macaé de Cima, Nova Friburgo, Rio de Janeiro, Brasil. II - Leandra (Miconieae). Rodriguésia 62: 629-662.

BFG. 2015. Growing knowledge: an overview of Seed Plant diversity in Brazil. Rodriguésia 66: 1085-1113.

Blaser, J.; Salimena, F.R.G. \& Chautems, A. 2012. Gesneriaceae na Serra Negra, Minas Gerais, Brasil. Rodriguésia 63: 705-714.

Candido, C.P. 2005. A família Melastomataceae na Serra do Cabral, MG: tribos Melastomeae, Merianieae e Miconieae. Dissertação de Mestrado. Universidade Estadual de Campinas, São Paulo. 88p.

Chiavegatto, B. \& Baumgratz, J.F.A. 2007. A família Melastomataceae nas formações campestres do Parque Estadual do Ibitipoca, Minas Gerais, Brasil. Boletim de Botânica da Universidade de São Paulo 25: 195-226.

Chiavegatto, B. \& Baumgratz, J.F.A. 2008. Meriania (Melastomataceae; Merianieae) no Rio de Janeiro, Brasil. Rodriguésia 59: 899-913.

Clausing, G. \& Renner, S.S. 2001. Molecular phylogenetics of Melastomataceae and Memecylaceae: implications for character evolution. American Journal of Botany 88: 486-498.

Drummond, G.M,; Martins, C.S.; Machado, A.B.M.; Sebaio, F.A. \& Antonini, Y. (orgs.). 2005. Biodiversidade em Minas Gerais: um atlas para a conservação. Fundação Biodiversitas, Belo Horizonte. 222p.

Dutra, S.M.; Salimena, F.R.G. \& Menini Neto, L. 2012. Annonaceae na Serra Negra, Minas Gerais, Brasil. Rodriguésia 63: 785-793.

Empresa de Assistência Técnica e Extensão Rural do Estado de Minas Gerais - EMATER. 2003. Projeto APA da Serra do Funil. EMATER, Rio Preto. 63p.

Faria, C.A.; Romero, R. \& Leoni, L.S. 2006. Flora fanerogâmica do Parque Nacional do Caparaó: Melastomataceae. Pabstia 17: 1-31.

Feliciano, E.A. \& Salimena, F.R.G. 2011. Solanaceae na Serra Negra, Rio Preto, Minas Gerais. Rodriguésia 62: 1-22. 
Fritsch, P.W.; Almeda, F.; Renner, S.S.; Martins, A.B. \& Cruz, B.C. 2004. Phylogeny and circumscription of the near-endemic Brazilian tribe Microlicieae (Melastomataceae). American Journal of Botany 91: 1105-1114.

Goldenberg, R.; Baumgratz, J.F.A. \& Souza, M.L.D.R. 2012a. Taxonomia de Melastomataceae no Brasil: retrospectiva, perspectivas e chave de identificação para os gêneros. Rodriguésia 63: 145-161.

Goldenberg, R.; Fraga, C.N.; Fontana, A.P.; Nicolas, A.N. \& Michelangeli, F.A. 2012b. Taxonomy and phylogeny of Merianthera (Melastomataceae). Taxon 61: 1040-1056.

Gonçalves, E.G. \& Lorenzi, H. 2007. Morfologia vegetal: organografia e dicionário ilustrado de morfologia das plantas vasculares. Instituto Plantarum, Nova Odessa. 416p.

Gonzaga, D.R.; Zappi, D.; Menini Neto, L. \& Furtado, S.G. 2014. Cactaceae da Serra Negra, Minas Gerais, Brasil. Rodriguésia 65: 443-453.

Harris, J.G. \& Harris M.W. 2001. Plant identification terminology - an illustrated glossary, $2^{\text {nd }}$ ed. Spring Lake Publishing, Spring Lake. 216p.

Kinoshita, L.S.; Martins, A.B. \& Bernardo, K.F.R. 2007. As Melastomataceae do município de Poços de Caldas, Minas Gerais, Brasil. Hoehnea 34: 447-480.

Leoni, L.S. \& Tinte, V.A. 2004. Flora do Parque Estadual da Serra do Brigadeiro: caracterização da vegetação e lista preliminar das espécies. Vol. 1. Gráfica São José, Carangola. 91p.

Martins, A.B. 2009a. Melastomataceae. In: Wanderley, M.G.L.; Shepherd, G.J.; Melhem, T.S.; Giulietti, A.M. \& Martins, S.E. (eds.). Flora fanerogâmica do estado de São Paulo. Instituto de Botânica, São Paulo. Vol. 6, pp. 1-4.

Martins, A.B. 2009b. Cambessedesia DC. In: Wanderley, M.G.L.; Shepherd, G.J.; Melhem, T.S.; Giulietti, A.M. \& Martins, S.E. (eds.). Flora fanerogâmica do estado de São Paulo. Instituto de Botânica, São Paulo. Vol. 6, pp. 15-17.

Martins, A.B. 2009c. Lavoisiera DC. In: Wanderley, M.G.L.; Shepherd, G.J.; Melhem, T.S.; Giulietti, A.M. \& Martins, S.E. (eds.). Flora fanerogâmica do estado de São Paulo. Instituto de Botânica, São Paulo. Vol. 6, pp. 29-30.

Martins, A.B. 2009d. Rhynchanthera DC. In: Wanderley, M.G.L.; Shepherd, G.J.; Melhem, T.S.; Giulietti, A.M. \& Martins, S.E. (eds.). Flora fanerogâmica do estado de São Paulo. Instituto de Botânica, São Paulo. Vol. 6, pp. 120-124.

Martins, E. 2009. Trembleya DC. In: Wanderley, M.G.L.; Shepherd, G.J.; Melhem, T.S.; Giulietti, A.M. \& Martins, S.E. (eds.). Flora fanerogâmica do estado de São Paulo. Instituto de Botânica, São Paulo. Vol. 6, pp. 150-153.

Matozinhos, C.N. \& Konno, T.U.P. 2011. Diversidade taxonômica de Apocynaceae na Serra Negra, MG, Brasil. Hoehnea 38: 569-595.
Matsumoto, K. \& Martins, A.B. 2005. Melastomataceae nas formações campestres do município de Carrancas, Minas Gerais. Hoehnea 32: 389-420.

Menini Neto, L.; Matozinhos, C.N.; Abreu, N.L.; Valente, A.S.M.; Antunes, K.; Souza, F.S.; Viana, P.L. \& Salimena, F.R.G. 2009. Flora vascular não-arbórea de uma floresta de grota na Serra da Mantiqueira, Zona da Mata de Minas Gerais, Brasil. Biota Neotropica 9: 149-161.

Mezzonato-Pires, A.C.; Salimena, F.R.G. \& Bernacci, L.C. 2013. Passifloraceae Juss. ex Russel na Serra Negra, Minas Gerais, Brasil. Rodriguésia 64: 123-136.

Oliveira, J.A.; Salimena, F.R.G. \& Zappi, D. 2014. Rubiaceae da Serra Negra, Minas Gerais, Brasil. Rodriguésia 65: 471-504.

Oliveira-Filho, A.; Fontes, M.A.L.; Viana, P.L.; Valente, A.S.M.; Salimena, F.R.G. \& Ferreira, F.M. 2013. O mosaico de fitofisionomias do Parque Estadual do Ibitipoca. In: Flora do Parque Estadual do Ibitipoca e seu entorno. Forzza, R.C.; Menini Neto, L.; Salimena, F.R.G. \& Zappi, D. (orgs.). Editora UFJF, Juiz de Fora. Pp. 53-93.

Radford, A.E. 1986. Fundamentals of plant systematics. Harper \& Row, New York. 494p.

Renner, S.S. 1993. Phylogeny and classification of the Melastomataceae and Memecylaceae. Nordic Journal of Botany 13: 519-540.

Rezende, A.R.; Romero, R. \& Goldenberg, R. 2014. Sinopse de Miconia seção Miconia DC. (Melastomataceae) no estado de Minas Gerais, Brasil. Bioscience Journal 30: 273-287.

Rocha, G.C. 2013. O meio físico da região de Ibitipoca: características e fragilidades. In: Flora do Parque Estadual do Ibitipoca e seu entorno. Forzza, R.C.; Menini Neto, L.; Salimena, F.R.G. \& Zappi, D. (orgs.). Editora UFJF, Juiz de Fora. Pp. 27-52.

Rodrigues, K.F. 2009. Estudos taxonômicos em Cambessedesia DC. (Melastomataceae). Tese de Doutorado. Universidade Estadual de Campinas, Campinas. 248p.

Rolim, T.P. 2011. Melastomataceae Juss. no campo rupestre do Parque Estadual do Iatacolomi, Minas Gerais, Brasil: relações ecológicas fitofisionômicas, padrões de distribuição geográfica e comparação florística. Dissertação de Mestrado. Universidade Federal de Viçosa, Viçosa. 90p.

Romero, R. \& Martins, A.B. 2002. Melastomataceae do Parque Nacional da Serra da Canastra, Minas Gerais, Brasil. Revista Brasileira de Botânica 25: 19-24.

Romero, R. \& Versiane, A.F.A. 2014. A new species of Microlicia and a checklist of Melastomataceae from the mountains of Capitólio municipality, Minas Gerais, Brazil. Phytotaxa 170: 118-124.

Salimena, F.R.G.; Matozinhos, C.N.; Abreu, N.L.; Ribeiro, J.H.C.; Souza, F.S. \& Menini Neto, L. 2013. Flora fanerogâmica da Serra Negra, Minas Gerais, Brasil. 2013. Rodriguésia 64: 311-320. 
Semir, J.; Martins, A.B. \& Chiea, S.C. 1987. Melastomataceae. In: Giulietti, A.M.; Menezes, N.L.; Pirani, J.R.; Meguro, M. \& Wanderley, M.G.L. Flora da Serra do Cipó, Minas Gerais: caracterização e lista das espécies. Boletim de Botânica da Universidade de São Paulo 9: 72-78.

Silva, M.A.O. \& Romero, R. 2008. Melastomataceae das serras do município de Delfinópolis, Minas Gerais, Brasil. Rodriguésia 59: 609-647.
Souza, F.S.; Salino, A.; Viana, P.L. \& Salimena, F.R.G. 2012. Pteridófitas da Serra Negra, Minas Gerais, Brasil. Acta Botanica Brasilica 26: 378-390.

Valente, A.S.M.; Garcia, P.O.; Salimena, F.R.G. \& Oliveira-Filho, A. 2011. Composição, estrutura e similaridade florística da Floresta Atlântica, na Serra Negra, Rio Preto - MG. Rodriguésia 62: 321-340. 